\title{
Ignacio Ellacuría y la \\ జّ "civilización de la pobreza". Apuntes para el siglo XXI'
}

\section{Ángel Sermeño Quezada Universidad Autónoma de la Ciudad de México}

Resumen: Este ensayo ofrece una reconstrucción de la categoría "civilización de la pobreza" en el pensamiento de Ignacio Ellacuría. Por tal categoría se entiende la propuesta de construcción de un orden global de convivencia humana que surge en oposición y como respuesta a la grave crisis civilizatoria que padecemos. Si hace treinta años la emergencia de esta crisis ya era evidente, ahora es imposible no reconocer que vivimos tiempos que nos ponen frente a los ojos complejos desafíos de toda indole: financieros, económicos, ambientales, climáticos, alimentarios, demográficos, energéticos, etcétera. De ahi que con esta noción Ellacuría subrayaba ya de manera imperativa la necesidad impostergable de construir un futuro radicalmente distinto para la humanidad. En su concepción de civilización de la pobreza Ellacuría insistió en buscar la manera de establecer un sistema de vida factible caracterizado por articular una relación apropiada entre el hombre y la naturaleza. Asi el nuevo eje de articulación de la noción de civilización sería la conexión profunda entre civilización y sustentabilidad. Conseguir este equilibrio ecológico-sustentable no es una tarea sencilla y para Ellacuría su viabilidad inicia con una radical crítica al modelo civilizatorio apitalista imperante.

Palabras clave: Capitalismo, sustentabilidad, bienestar, pobreza, civilización, justicia.

Abstract: This article offers a reconstruction of the category of "civilization of poverty" in the thought of Ignacio Ellacuria. For such category, we understand the proposal of the construction of a global order of human cohabitation that emerges in opposition and as a response to the serious civilizatory crisis we currently suffer. If thirty years ago, the emergence of such crisis was evident, now it is impossible not to recognize that we live in times that face us with complex challenges of all sorts: financial, economic, environmental climatic, food-related, demographical, energetic, etc. Thus, with such a notion Ellacuria already underscored the urgent need of constructing a radically different future 
for humanity. In his conception of civilization of poverty, Ellacuria insisted in searching for a way of establishing a viable system of life, characterized by articulating an appropriate link between humankind and nature. Thus, the new axis of articulation of the notion of civilization would be the intimate connection between civilization and sustainability. Achieving this ecological-sustainable balance is not an easy task and, for Ellacuria, its viability starts with a radical critique of the current capitalist civilizatory model.

Key words: Capitalism, sustainability, welfare, poverty, civilization, justice.

"Revertir la historia, subvertirla y lanzarla en otra dirección"

Ignacio Ellacuría

\section{Introducción}

Eric Hobsbawn propuso la distinción entre siglos cortos y siglos largos. De ser correcta su propuesta, Ignacio Ellacuría fue un habitante del corto siglo XX (1918-1989) que abarcó el lapso sociohistórico entre el final de la primera guerra mundial y la caída del muro de Berlín. Toda la vida de Ignacio Ellacuría (19301989), especialmente su vida adulta, transcurrió, pues, bajo el paraguas de la guerra fría. Y, además, se desenvolvió mayoritariamente desde un lugar, periférico, marginal, limítrofe, del mundo, Centroamérica.

Han transcurrido treinta años de su muerte martirial. El mundo ha cambiado acelerada y hondamente. Ese cambio, de cierto puede decirse, no ha sido para mejor sino para peor. En efecto, las causas contra las que Ellacuría luchó, por las que vivió y por las que dio la vida ( contra la pobreza, la dominación de los poderosos sobre los débiles, la injusticia estructural, etcétera) persisten imbatibles expresando viejos y nuevos rostros. Ello aporta cierta dificultad a la conmemoración de su desaparición física que hoy nos convoca. Vivimos, ya entrados con contundencia en el siglo $X X I$, en un mundo en transición $\mathrm{y}$, por ende, en un mundo que no ofrece contornos claros para su interpretación. Que le llamemos a nuestro tiempo "posmoderno", "poshistórico", "posdemocrático", o "poscapitalista" da cuenta de esa referida ambigüedad. Al mismo tiempo, este rasgo permite enfatizar y revalorar la importancia del legado de la vida y obra de Ellacuría en lo que expresa de innegable actualidad en este nuestro mundo confuso y ambivalente en el que nos encontramos. Porque Ellacuría sigue vivo y activo, tanto en su pensamiento como también en su ejemplo biográfico. $^{2}$ 


\section{Mi recuerdo de Ignacio Ellacuría}

Por ello, me detendré en primer lugar, así sea de forma esquemática y fugaz en resaltar el aspecto biográfico dando por supuesto que el auditorio se encuentra familiarizado al menos de forma general con el mismo. Ante todo, me permitiré un comentario personal y diré que ha sido un regalo de vida haber tenido a Ignacio Ellacuría como mi maestro en los años formativos de juventud cuando estudié filosofía. Insisto en que conocer un poco de la biografía de Ellacuría es muy importante para entender a profundidad su pensamiento en sus principales vertientes, filosófica, teológica y, especialmente,

de la gran congruencia entre este pensamiento y su condición de hombre de comprometida acción ético-política en la esfera pública. Una congruencia del discurso yactuar personal muy difícil de alcanzar y sostener y que, por tanto, se observa muy poco en el mundo político, académico o de fe. Yo destacaría la sinceridad y hondura de su fe cristiana la que da unidad y sentido a su legado. Me apropio en este sentido de una concisa pero honda elaboración del perfil de Ellacuría elaborada por el padre David Fernández en 2004:

Lo primero que hay que decir es que Ellacuría era un hombre complejo, que en su persona realizó síntesis muy elaboradas de mundos antagónicos: tenía, por ejemplo, una formación clásica, como la de cualquier jesuita, pero conocía los modernos análisis de la sociedad; era profundamente europeo, pero entendió como pocos la realidad latinoamericana; primermundista, y abogó sin descanso por los derechos del Tercer Mundo; pertenecía a la elite universitaria pero entregó su vida por los derechos de las mayorias populares que jamás pisaron una universidad; poco dado a dejar ver sus sentimientos y sin embargo mostró una enorme sensibilidad por el sufrimiento humano; de formación filosófica especulativa y fue un administrador universitario y un negociador político consumado; siempre vivió en Occidente pero conoció el marxismo y su desarrollo en Europa del Este a profundidad; trabajador incansable que, a pesar de su intensidad, seguía desde El Salvador todos los partidos de su equipo el Athletic de Bilbao... Eclesialmente, Ellacuria vivió y consumó en su persona la transición de la Iglesia preconciliar a la Iglesia posconciliar, de la Compañia de Jesús antigua y avejentada a la Compañia de Jesús implicada en los cambios políticos más revolucionarios. Imposible, pues, definir a Ellacuría con unos cuantos rasgos. (Fernández, 2004). 
Si combinamos ese perfil sintético con el contenido de los escritos y estudios publicados que dan a su obra unidad y sentido podemos hablar al menos de tres dimensiones sustantivas de Ellacuría: el filósofo, el teólogo y el hombre público que actúo políticamente en el horizonte histórico salvadoreño, centroamericano y latinoamericano. Enumero unas rápidas viñetas al respecto. En primer lugar, esta, por ejemplo, el Ellacuría filósofo quien dejó inconcluso el proyecto en construcción de una filosofía propia. Una filosofía latinoamericana y al mismo tiempo, como toda filosofía, una filosofía universal. Esta, por supuesto, el Ellacuría teólogo de la liberación. Sería este quizá el Ellacuría académico, pensador sistemático y con mayor riqueza de legado intelectual. Esta el Ellacuría político en cuyo perfil se traslapan subdimensiones muy complejas e interesantes. De ellas la más visible es el Ellacuría rector y de la que difícilmente se puede separar el Ellacuría negociador, es decir, el Ellacuría pontífice, el diplomático, el hábil constructor de salidas, de soluciones políticas a los inconmensurables conflictos del poder. Evidentemente, todos estos Ellacuría como ya adelantaba son uno solo. Son el jesuita, el hombre de fe, el discípulo de Jesús y de Ignacio de Loyola, el digno hijo, pues, de la Compañía de Jesús. De este hombre que se me permitió conocer es del que al menos quiero reseñar fugaz- mente su dimensión público-política que les comento.

Ellacuría dedicó la última década de su vida a trabajar con tesón y sin regatear riesgos a encontrar los consensos y acuerdos que acabaran mediante una negociación política con la guerra civil salvadoreña. Y ello lo hizo con gran brillantez y clarividencia. Por supuesto, tal actividad no la desplegó como si fuese un actor iluso o ingenuo. Al contrario, en su praxis estrictamente política exhibió una alta comprensión de la política. Es decir, no esa mediocre concepción instrumental de la política emanada de la ciencia política empírica que ramplonamente la entiende como una vulgar aritmética del poder; sino como siempre debe entenderse, aunque suene a lugar común, la política como un arte. El arte de la perspicacia, de captar el curso de los acontecimientos y las alternativas, de leer el "signo de los tiempos"; y ello, sin dejarse doblegar por las pasiones, los intereses, los espejismos y las incompetencias de los actores enfrascados en la lucha. Bajo tal tesitura, dialogó con todos los actores y fuerzas involucradas en el conflicto bélico. Desde los mandos guerrilleros a los altos mandos castrenses, los sectores empresariales, los líderes de los partidos políticos, tanto aquellos que sobrevivían en el exilio como los que operaban como fuerzas funcionales al régimen, $y$, por supuesto, también 
con los actores de la sociedad civil, es decir, sindicatos movimientos sociales, etcétera.

El precio que pago (él, sus hermanos jesuitas, la UCA y la Compañía de Jesús) por involucrarse en la empresa de la salida negociada al conflicto lo conocemos. Al final, el sacrificio de la comunidad de la UCA fue ese imperceptible golpe de pulgar con que se dirimió la salida al conflicto. Para quienes los conocimos nos pareció un precio cruel y desmesurado. Matemáticamente, Ignacio Ellacuría podría estar vivo. Tendría 89 años y habría tenido la oportunidad de profundizar sus análisis, interpretaciones y propuestas para la construcción de salidas a las varias y hondas crisis que ahora enfrentamos. Es decir, habría probablemente legado a través de la brillantez de su pensamiento unos contornos más precisos y concretos que ya no alcanzo a proponer sino solo a esbozar de una civilización de la pobreza en oposición a la imposición del neoliberalismo y la globalización con todas sus negativas secuelas. ${ }^{3}$

Ciertamente, en tanto hombre de $\mathrm{fe}$, el legado intelectual y humano de Ellacuría manifiesta un talente profético, de crítica intransigente ante la injusticia y de demanda imperativa de solución y/o corrección a eso que se crítica. Por eso es también un legado utópico en el sentido más positivo y constructivo de la palabra. Más adelante volveré sobre la forma como Ellacuría evitaba desencarnar - desconectar ambas nociones de utopía y profetismo para que no perdiesen su efectividad histórica, cosa que inevitablemente ocurre cuando se utilizan por separado.

\section{Sobre la noción de civilización de la pobreza}

Dice Jon Sobrino que la categoría civilización de la pobreza fue acuñada ya en plena etapa de madurez del pensamiento de Ellacuría. Es decir, no contiene temas, ni reflexiones juveniles y pasajeras. Sin embargo, ha resultado ser hasta el momento una categoría más bien ignorada por los estudiosos de dicho legado. Por supuesto, este Ellacuría "olvidado" tiene mucho que ofrecer por lo que el descuido en el estudio de este aspecto de su obra es "empo- brecedor" e "irresponsable" ya que este Ellacuría "puede seguir siendo un aguijón socrático, incómodo, pero también positivo y necesario en el mundo actual" (Sobrino, 2005: 210).

Tal injustificado olvido quizá pueda explicarse porque Ellacuría, como con otros conceptos centrales de su pensamiento e, embuído como siempre estuvo en muchas tareas y frentes, no alcanzó a desarrollarlo sistemáticamente. Sin embargo, el 
contenido esencial del concepto quedo suficientemente perfilado.

Por civilización de la pobreza entiende un orden global de convivencia humana que surge en oposición y como respuesta a la grave crisis civilizatoria que padecemos. Si hace treinta años la emergencia de esta crisis ya era evidente, ahora es imposible no reconocer que vivimos tiempos que nos ponen frente a los ojos desafíos de toda índole: financieros, económicos, ambientales, climáticos, alimentarios, demográficos, energéticos, etcétera. "¿Como lograr desde la cultura un mundo mejor?" se preguntaba Ellacuría en un breve discurso que pronunció en 1988 ante la Academia de Artes de Berlín (Escritos teológicos I, 2000. p. 349). Fue este un discurso en donde él subrayaba ya de manera imperativa la necesidad impostergable de construir un futuro radicalmente distinto para la humanidad. Examinemos esta tesis con pasos más detenidos.

Desde el sentido común se suele oponer civilización a barbarie, en donde barbarie es sinónimo de atraso, primitivismo, oscurantismo. En cambio, civilización es sinónimo de evolución, avance, ilustración y/o modernidad. Es decir, la civilización así invocada hace referencia a sociedades más avanzadas, complejas y en donde la humanidad ha alcanzado los mayores niveles de desarrollo y progreso. Pero este uso de sentido común del concepto de civilización es acrítico y su utilización es ideologizante en el sentido de que la propia palabra en sí tiende a ocultar los muchos males estructurales ocasionados por la propia civilización occidental (industrial, capitalista, posmoderna).

En su concepción de civilización de la pobreza, Ellacuría se adelantó a un emergente y correctivo uso de la noción de civilización que se abre camino en nuestros días. En esta nueva concepción, la civilización consistiría en el establecimiento de un sistema de vida factible; es decir, las sociedades civilizadas serían aquellas capaces de construir una relación apropiada entre el hombre y la naturaleza. Así, el nuevo eje de articulación de la noción de civilización sería la conexión profunda entre civilización y sustentabilidad. Conseguir este equilibrio ecológicosustentable no es una tarea sencilla y para Ellacuría su viabilidad inicia con una radical crítica al modelo civilizatorio capitalista imperante. Por ello, como ya afirmaba, la noción de civilización de la pobreza se construye en oposición a la civilización de la riqueza. Es decir, surge de una contraposición dialéctica entre pobreza y riqueza.

Es, pues, necesario realizar una operación crítica que "desenmascare" a la civilización de la riqueza. Esta afirmación nos puede parecer excesiva o, al menos demagógica. Pero ello 
solo si se le se le mira superficialmente sin ponerle la atención que merece. La verdad es que la manera autocomplaciente y hasta cínica con la que la civilización occidental se describe justifica y autocomprende es, ya desde los tiempos en vida de Ellacuría, un discurso insostenible de legitimación. Si Ellacuría opuso una civilización de la pobreza a su contraria de la riqueza fue porque Ellacuría enfiló su crítica al sistema capitalista sobre el que se erige la civilización occidental.

Para Ellacuría (y para muchos otros, empezando por Carlos Marx, la verdad sea dicha) el capitalismo ha traído males mayores que beneficios a la humanidad y sus procesos de autocorrección nunca han dado suficientes muestras de corregir $y / 0$ revertir su nociva trayectoria. De los varios argumentos que Ellacuría esboza en contra de la civilización de la riqueza se destacan dos: 1) El capitalismo no satisface las necesidades básicas de todos y no genera espíritu, ni valores que humanicen a las personas y las sociedades; y 2) Las promesas de la civilización de la riqueza no pueden ser universalizables. Como se ve, se trata de una crítica estructural al sistema en su conjunto. El nivel de vida (consumo y bienestar) utiliza una cantidad de recursos materiales que matemáticamente no pueden ser distribuidos por igual entre todos los integrantes de la humanidad. Es decir, el nivel de vida de las sociedades ricas no es, como se reitera, universalizable. Las sociedades ricas ubicadas en el cuadrante noratlántico del planeta (incluyendo, evidentemente, a Australia y Nueva Zelanda) consumen tal cantidad de recursos, materias primas y energía que no pueden alcanzar para toda la población mundial. Para decirlo utilizando las propias palabras de Ellacuría:

Pues bien, lo que parece ser la raíz originaria de los males del mundo presente, tal vez pudiera definirse como civilización de la riqueza, entendido el término riqueza en toda su complejidad. No en vano dividimos el mundo entre países ricos y países pobres, entre sectores ricos y sectores pobres. La civilización dominante en nuestro mundo, no obstante, las diferencias que se dan en él, está construida básicamente sobre la necesidad de acumular; se piensa y se estima que sólo la acumulación de riqueza puede ofrecer seguridad personal, libertad, posibilidad de no ser dominado por los otros y dominar a los demás, posibilidad última de alcanzar el poder, la estima, el placer y aun la capacidad misma de desarrollo cultural. Y, lo que es más grave, no se trata de un fenómeno tan sólo personal o colectivo, que surja primariamente de una opción razonada y libremente escogida, sino que se trata más bien de haber dejado que la 
dinámica propia del capital se convierta en la fuerza dominante de nuestro mundo, tomado éste como un todo y aceptadas las diferencias dadas dentro de ese todo. Pudiera decirse que en el globo lo económico determina en última instancia todo lo demás, pero entendiendo lo económico como determinado a su vez por la acumulación de capital. No sólo se sitúa la dinámica del capital sobre la naturaleza del trabajo, sino que se desvirtúa el trabajo mismo y se lo valora conforme a su capacidad de acumular capital. El problema es ciertamente complejo y no admite simplificaciones, pero tampoco puede ser arrinconado a la hora de construir un futuro nuevo. (Ellacuría, Escritos teológicos 1, 2000: 351).

Una solución auténtica, profunda, a los males del capitalismo pasa por la construcción de una civilización de la pobreza. Aquí lo primero que debe destacarse es que Ellacuría no propone una suerte de retroceso hacia un mundo de pauperización universal. No se trata, pues, de sugerir construir una economía de la pobreza, aunque si supone imaginar un modelo de austeridad compartida a nivel global y que consistiría en encontrar una manera de repartir los recursos y la riqueza más equitativamente. Esto necesariamente pasa por exigir a los habitantes de los países ricos adoptar y aceptar limitaciones en su estilo de vida.

Ellacuría admite que utilizar el adjetivo pobreza resulta no solo incomodo sino provocador para los beneficiarios del sistema capitalista. $Y$ lo es porque pone el acento en un dato que se quiere ignorar o eludir y que ya ha sido mencionado. Esto es que el mundo en su inmensa mayor parte se encuentra sumergido en unos niveles de pobreza y miseria que son inaceptables. En este sentido, sostiene que "la civilización de la pobreza no se denomina así porque propugne una vida materialmente miserable... sino porque es su negación superadora y no simplemente una búsqueda de la pobreza por sí misma" (Ellacuría, Escritos teológicos I, 2000: 352). Conviene advertir que en Ellacuría pobreza significa lo que a todos nos denota el concepto, es decir, ausencia o privación de lo necesario para vivir dignamente, pero también para este autor tal noción es susceptible de incorporar dos sentidos adicionales: "pobreza como apertura espiritual a Dios" y "pobreza en cuanto solidaridad con los pobres y participación en su lucha por la justicia”. (Maier, 2013: 215).

En todos estos usos y en positivo, la civilización de la pobreza tendría como objetivo 
crear no solo un orden económico mundial nuevo, en el cual las relaciones de intercambio fuesen más justas, sino una civilización nueva, que ya no esté edificada sobre los pilares de la hegemonia y dominación, de la acumulación y la diferencia, del consumismo y del bienestar falseado, sino sobre pilares más humanos y más cristianos (Ellacuría, 2000, Escritos teológicos II: 300).

Es decir, Ellacuría consideraba necesario e impostergable:

construir un estado universal de cosas, en que éste garantizada la satisfacción de las necesidades fundamentales, la libertad de las opciones personales y un ámbito de creatividad personal y comunitaria que permita la aparición de nuevas formas de vida y cultura, nuevas relaciones con la naturaleza, con los demás hombres, consigo mismo y con Dios" (Ellacuría, 2000, Escritos teológicos (I: 303).

Ellacuría no era ingenuo. Sabía bien que su propuesta contenía una elevada dosis de utopíay, sin embargo, sostenía que ello no la invalidaba. Pero, además, debemos enfatizar que él la concebía desde su condición de hombre de fe. Es decir, la civilización de la pobreza sostiene sus eventuales contenidos sociológicos e históricos sobre bases teológicas que la hacen deudora en específico de la teología de la liberación. Es por ello qué la concepción de una civilización de la pobreza trata de un tema de madurez en Ellacuría dado que presupone todo el proceso de transformación del discurso teológico convencional hacia las innovaciones y reformulaciones conceptuales que la teología de la liberación incorporó al mismo. ${ }^{4}$

En concreto, para Martin Maier dicha fundamentación teológica radicaría en desarrollos conceptuales previos de Ellacuría tales como su "teología de la historia, su fundamentación teologal y cristológica de la opción de los pobres, y su soteriología histórica, en cuyo centro se encuentra el pueblo crucificado, como el signo de los tiempos más importante y como el portador histórico de la salvación" (Maier, 2014: 220). Jon Sobrino también ha dedicado en los últimos años un importante espacio en sus escritos para recuperar el apuntalamiento teológico de Ellacuría a la civilización de la pobreza. De ellos, quizá, el que mejor engloba este efecto de fundamentación sea, precisamente, el de pueblo crucificado (Sobrino, XXX).

Brevemente diré que para Sobrino el pueblo crucificado en la concepción de Ellacuría es una expresión 
tanto negativa como positiva de la realidad histórica que define a muchos pueblos a nivel global. En el sentido negativo es una lectura teológica de la condición del pobre. Evidentemente, se trata de inmensas mayorías en condición de pobreza que son en los hechos pueblos transidos de muerte producto de la injusticia. Hay que añadir, algo de lo que nos damos cuenta, pero preferimos ignorar cínicamente, y es que estos pueblos pobres crucificados son pueblos ignorados, anulados a los que se les niega la palabra 0 , en lenguaje contemporáneo, se les niega el reconocimiento. Es decir, el nombre y, con ello, la existencia Simplemente comparemos el reconocimiento a la insurgencia del pueblo chileno y la insignificancia concedida a la misma insurgencia del pueblo haitiano que le proporcionan los medios de comunicación globales en sus coberturas y atención. ${ }^{5}$ Tal falta de reconocimiento tiene una función política evidente. Permite que los países ricos y sus habitantes puedan desentenderse sin mala conciencia de lo que su concentración de riqueza y niveles de consumo provocan en las inmensas mayorías de pobres y desposeídos de los países periféricos.

Sin embargo, como positividad, el pueblo crucificado expresa su mayor capacidad de renovación. Ellacuría afirma convencido que el pueblo crucificado trae salvación. Es decir, es una categoría que ofrece "luz" a la civilización de la riqueza, en el sentido de que le permite verse o reconocerse en su "verdad". El pueblo crucificado, nos recuerda Sobrino, fue concebido por Ellacuría como una metáfora. La metáfora de un espejo invertido que refleja la verdad del primer mundo. Una verdad desfigurada pero dolorosamente real en la pobreza y la miseria que el primer mundo se niega a reconocer y trata de disimular u ocultar.

El pueblo crucificado también aporta un segundo elemento de "salvación" que a simple vista parecería inverosímil y hasta seria causa de ocasionar estupor. Este elemento es la esperanza. Los pobres ofrecen esperanza a los ricos del primer mundo. El argumento es muy simple $y$, a pesar de las apariencias, no carece de congruencia lógica. Desde su sufrimiento, el tercer mundo genera y mantiene esperanza, misma que ofrece a un primer mundo que no la posee.

Me gustaría cerrar este apartado con un resumen esquemático de lo dicho hasta ahora: la civilización de la pobreza es: 1. Una utopía específica basada en un humanismo materialista transformado por la inspiración cristiana. 2. Que exige ser trabajada, imaginada y construida, desde el mundo real. Por tanto, a la civilización de la pobreza no basta con predicarla, ni con anunciarla. 3. Ella aporta algo aparentemente intangible pero real, a saber: el introducir "espíritu" cris- 
tiano en la sociedad. O dicho en lenguaje secular abrir paso a la solidaridad. Finalmente, 4. La civilización de la pobreza no debe ser confesional.
Sin embargo, acepta explícitamente la inspiración cristiana. (Sobrino, $X X X)$. Paso a un último apartado de este discurso.

\section{Civilización de la pobreza y desafíos globales hoy}

Ellacuría no llegó a elaborar una propuesta concreta de transformación y/o conversión de la civilización de la riqueza a la de la pobreza. Admitía que la fundamentación ética que la sostiene no era suficiente para volverla realidad y, de hecho, en sus varias formulaciones siempre hay una clara demanda de trabajo, de poner manos a la obra, para que esa civilización de la pobreza y de la austeridad compartida llegase a ser realidad. Sin embargo, consideraba firmemente que ningún proyecto de cambio podría enfilarse con impulso y acierto hacia una nueva realidad sin que exista un horizonte de esperanza y con perspectivas de acción. ${ }^{6}$

En este sentido, cabe reconocer junto con Martín Maier que:"Los conocimientos científicos y las propuestas técnicas por sí solo no son suficientes para generar cambios fundamentales. Las revoluciones comienzan en la mente, en el pensar de manera distinta. Se necesita un cambio fundamental de la conciencia y de los valores relacionado con un nuevo modo de comprender la calidad de vida y del medio ambiente, la integración de factores ecológicos, en la idea de bienestar y progreso" (Maier, 2015: 226). Jon Sobrino, por su parte, estima que Ellacuría propuso dos formas fundamentales de emprender la transformación de la actual civilización, a saber: 1) por medio de "la creación de modelos económicos, políticos y culturales, que hiciesen posible una civilización del trabajo como sustitutiva de una civilización del capital". Y, 2) "Robusteciendo positivamente una característica fundamental de la civilización de la pobreza, la solidaridad compartida, en contraposición con el individualismo cerrado y competitivo de la civilización de la riqueza" (Sobrino, 2014: 147).

De todas maneras, persisten las dos objeciones que se han enfilado en contra de la noción de civilización de la pobreza. La primera, que es demasiado general y la segunda que es utópica. La primera es fácilmente contra replicable: no era tarea solo de Ellacuría llenar de contenido concreto mediante modelos o recetas esta suerte de mantra que hemos hecho nuestro respecto a que "otro mundo es posible", porque para Ellacuría no solo era posible, sino que otro mundo era y es "necesario". Y, quizás con más fracasos que aciertos, estas propuestas concretas existen en nuestro mundo de hoy. 
Por ejemplo, "la apertura de los países ricos a las exportaciones de los países pobres, la abolición de las subvenciones y ayudas a la agricultura de los países ricos, un impuesto a las transacciones financieras, según el modelo de la tasa Tobin, un impuesto sobre el uso de los bienes globales comunes o la creación de un fondo internacional humanitaria para combatir la extrema pobreza" (Maier, 2015: 225).

La segunda objeción parece más difícil de remontar. Pero no lo fue para Ellacuría quién en un texto publicado póstumamente "Utopía y profetismo" mostró como la utopía no era un simple recurso en el que se refugian posiciones subjetivistas $y / 0$ transcendentalistas que son en realidad refractarias y elusivas de los futuros que están por advenir. La utopía para tener efectividad histórica, según Ellacuría, tiene que estar unida a la actitud crítica y de denuncia que encarna el profetismo. Ambas, utopía y profetismo se potencian y ello acontece cuando se sitúan en el lugar histórico adecuado. Ese lugar histórico, como sabemos, es América Latina porque los países hegemónicos que encarnan la civilización de la riqueza son, en opinión de Ellacuría, culturas envejecidas en donde solo hay lugar para que subsista el pragmatismo y el egoísmo. Cito unos breves párrafos que ilustran las afirmaciones anteriores:

El profetismo es protesta, es lucha... se convierte en utopia histórica, que niega el presente y lanza hacia el futuro. Si se entra en la acción profética, se hace historia en la línea de la negación y de la superación y no de la evasión.

Por la vía del profetismo, aunque la utopía no sea plenamente realizable en la historia, no por eso deja de ser efectiva. Una utopía que no sea de algún modo animadora y aún efectora de realizaciones históricas no es una utopia, sino que es una visión idealista e ideologizada.

Lo dado necesita actualizarse. Actualizarlo significa dar realidad actual a lo que formalmente es una posibilidad histórica y que como tal puede ser tomada o dejada, leída de un modo o de otro. Lo que debe ser actualizado es, entonces, lo dado, pero la lectura e interpretación de lo dado, la opción por una parte o otra de lo dado, depende de un presente histórico y de unos sujetos históricos. La actualización histórica de la utopia ya dada, surge ante todo, de la interpelación (signos de los tiempos) que va dándose por el Espíritu en la historia. 
La utopía tiene un cierto carácter de ideal irrealizable de una vez por todas, pero al mismo tiempo tiene el carácter de algo realizable asintóticamente en un proceso permanente de aproximación y, por tanto, implica mediaciones teóricas y prácticas, que se toman más de la dimensión categorial de la historia. (Ellacuria, Misterium Liberationis, 1991: 397-398).

Civilización de la pobreza es, pues, un concepto utópico (aunque no solamente) que emana de la utopía cristiana, inspirada, por supuesto, en los valores del evangelio. Ellacuría fue, en este sentido, consciente y provocadoramente utópico. Pero más allá del poder existe este ingrediente "espiritual" sin el cual es impensable el poder siquiera imaginar resolver los graves problemas y desafíos del mundo de hoy.

Treinta años después, el mundo "gravemente enfermo" que Ellacuría contempló, con hondo realismo hay que decir, parece haber entrado en fase terminal. Cada vez quedan menos años para, si bien no evitar, al menos moderar el impacto del cambio climático, a las generaciones jóvenes de hoy, y no digamos a las del porvenir. Técnicamente, sabemos, existen alternativas, quizás suficientes, para lidiar con una amenaza tan aterradora. Sin embargo, los poderosos de este mundo de manera egoísta se oponen a todo lo que amenace sus privilegios, despilfarros y sus márgenes de ganancias. Por ello la transición a las energías limpias que suponen el abandono de la utilización de los recursos fósiles para generar energías continúan enfrentando desesperantes y absurdos retrasos.

En fin... el punto del argumento que quiero defender, ya expresado líneas arriba, es que tan importante como las soluciones técnicas a los males de la civilización de la riqueza son los avances y consolidación de valores espirituales, humanistas y cristianos que emanan de la civilización de la pobreza. Sin ellos nuestro mundo literalmente no parece tener salvación. Jon Sobrino habla de un nuevo "quicio", de un mínimo sustento que este nuevo espíritu puede aportar a los desafíos civilizatorios de hoy. De ese quicio destaca los elementos siguientes: 1. Estar en la realidad (no vivir en las islas de abundancia). 2. Honradez con lo real, superando mentira y encubrimiento con la voluntad de verdad. 3. La compasión ante el sufrimiento de inmensas mayorías, denunciando las injusticias que las produce. 4. Exigencia de una libertad de y para todos. 5. Cargar con el peso de la historia. 6. El gozo de sabernos todos hermanos. 7. El cuidado de la naturaleza y de toda la creación. 8. La esperanza utópica. (Sobrino, 2014: 149). 
Para concluir, me permito una última reflexión. Inicie este discurso invocando esa etapa de la historia mundial que llamamos guerra fría. Pienso que los muchos acontecimientos que hemos presenciado en estos treinta años muestran la actualidad y vigencia del legado del pensamiento de Ignacio Ellacuría. La caída del muro de Berlín y la expansión de la democracia que prometía cubrir todo el planeta resultó ser una victoria engañosa, incluso perversa. Es cierto que en todos estos años se suprimió la amenaza de un cataclismo nuclear (aunque con Donald Trump esa amenaza parece estar de regreso). Tal amenaza de aniquilación fue un hondo temor que nos acompañó de forma angustiosa desde el inicio de la carrera armamentista. Sin embargo, el triunfo de la democracia liberal, emblemáticamente representada junto con la caída del muro con el colapso de la Unión Soviética, significó el triunfo del capitalismo, quién ya sin adversarios con quién competir dio rienda suelta a sus dinámicas más inhumanas.

Opino, en este sentido, que los recelos, las críticas y las condenas hacia el capitalismo presentes en la obra de Ellacuría no han sido mas que confirmadas en estas tres décadas transcurridas. De la misma manera, hay que recordar que Ellacuría era muy crítico con la democracia liberal. No admitía los usos legitimadores que de ella hacían los países ricos, especialmente Estados Unidos, para apoyar y reproducir situación de injusticia y dominación. Me consta que Ellacuría se concentraba más en los usos y los efectos negativos de estos usos que la democracia provocaba en los pueblos y las naciones periféricas y pobres más que en el dejarse distraer por una consideración de los valores y los diseños institucionales que en abstracto volvieron a la democracia (elecciones, pluralismo de partidos, normas constitucionales que incluyen división de poder, libertades públicas asociadas a la ciudadanía liberal, sociedad civil, etcétera), incluso en nuestros días de desencanto con la misma, el principio universal de legitimidad de los regímenes políticos.

Pero quizás por ello Ellacuría no estaría tan sorprendido por el péndulo iliberal que hoy sacude al mundo. Los síntomas están ahí a la vista de todos y se incrementan en lugar de reducirse. Racismo, nacionalismo, xenofobia, terrorismo, populismo con sus expresiones extremas de violencia, fanatismo y exclusión. El hecho es que las dinámicas capitalistas de la globalización han configurado un mundo a su imagen semejanza. Un mundo en donde la economía subordina y domestica a la política y lo hace a través de eso que genéricamente llamamos neoliberalismo. No tengo ya espacio para discutir a fondo ese susodicho programa neoliberal (reducción del Estado y del gasto público; desregulación; privatización; expansión 
del mercado; monetarismo). Pero la interpretación que quiero compartir con ustedes es que la aplicación global de este programa ${ }^{7}$ es la que ha provocado como uno de sus principales efectos la concentración de la riqueza quizás solo comparable con la de finales del siglo XIX (Piketty, 2014).

Tal concentración de la riqueza ha sido posible no solo por el referido neoliberalismo que ha favorecido la desregulación financiera (recortes de impuesto a las grandes corporaciones y a las grandes fortunas y evasión de impuestos en paraísos fiscales) sino también por la revolución tecnológica (inteligencia artificial, robótica, etcétera). Las consecuencias mas visibles el aumento estratosférico de la desigualdad y el colapso de los ingresos reales de las clases medias y la precarización del trabajo. ${ }^{8}$

No pretendo ofrecer un diagnóstico completo de los grandes desafíos civilizatorios de hoy. Solo esbozo gruesas pinceladas de un horizonte A lo enunciado agregaría un viejo problema, el de la masiva migración de las regiones pobres a las ricas, que han adquirido dimensiones de crisis humanitarias de gran envergadura y, agregaría también, el tampoco tan nuevo pero ahora si de urgente aten- ción problema del cambio climático. Este último desafío en particular vuelve a colocar a la humanidad entera al borde de sus límites, es decir, al borde de la aniquilación de la especie. Personalmente soy más pesimista que optimista y no considero excesivos estos temores. Me parece que treinta años después de la desaparición física de Ellacuría el mundo, como ya dije, está peor, aunque, sin duda, coexistan voces que afirmen lo contrario, que se encuentra mejor.

Una cosa esta clara. Vivimos en un mundo marcado por un horizonte de confusión y desorientación. La humanidad enfrenta desafíos y peligros sin parangón. Parecería que navegamos en aguas embravecidas, a la deriva, sin rumbo. En ese navío vamos todos: ricos y pobres. Así, pienso que un contexto con estas características nos hace extrañar personalidades con la inteligencia, congruencia ética y espíritu cristiano como la de Ignacio Ellacuría. En la obra que nos ha legado, por ejemplo, en esta noción de civilización de la pobreza que hemos recordado, podemos acaso encontrar inspiración para ayudar a la humanidad a elaborar soluciones creativas para salir de este horizonte desajustado y caótico en el que hoy nos encontramos.

\section{Referencias bibliográficas}

- Aguilar Valenzuela, R. (2013), "Los jesuitas actores políticos de su tiempo", en: Castro Soto, O. y Flores García, V. El puño y el verbo. El legado jesuita 
de Centroamérica al mundo, UCA/Editores y Universidad Iberoamericana Puebla, págs. 167-174.

- Ellacuría, I. (1991) “Utopía y profetismo”, en Ellacuría, I. y Sobrino, J., et. al. Misterium liberationis. Conceptos fundamentales de la teología de la liberación, San Salvador, UCA/Editores, págs. 393-442.

- Ellacuría, I. (2000) "El reino de Dios y el paro en el tercer mundo", en Escritos teológicos /I. San Salvador, UCA/Editores, págs. 395-305.

- Ellacuría, I.(2000) “La construcción de un futuro distinto para la humanidad”, en Escritos teológicos I, San Salvador, UCA/Editores, págs. 347-334.

- Ellacuría, I. (2001) “Misión actual de la Compañía de Jesús”, en Escritos teológicos IV, San Salvador, UCA/Editores, págs. 235-250.

- Fernández, D. (2004) “Ignacio Ellacuría: vida, pensamiento e impacto en la universidad jesuita de hoy", Discurso pronunciado en la Universidad Iberoamericana Ciudad de México el 24 de noviembre de 2004. (Inédito)

- Flores García, V. (2013) “Las ideas olvidadas de Ignacio Ellacuría”, en Castro Soto, O. y Flores García, V. El puño y el verbo. El legado jesuita de Centroamérica al mundo, UCA/Editores y Universidad Iberoamericana Puebla, págs. 175-202.

- Maier, M. (2015) "La civilización de la pobreza y los desafíos globales hoy”, en Ashley, M. Cardenal, R. y Maier, M. (Ed.) La civilización de la pobreza. El legado de Ignacio Ellacuría para el mundo de hoy, San Salvador, UCA/ Editores, págs. 213-232.

- Piketty, Th. (2014) El capital en el siglo XXI, México, FCE.

- Sermeño, A. (2003) “Teología, liberación y poder”, en Metapolítica, números 26-27 Págs. 91-98.

- Sobrino, J. (2014) "Civilización de la pobreza contra civilización de la riqueza para revertir un mundo gravemente enfermo", en Papeles de relaciones ecosociales y cambio global, Número 125: 139-150.

- Sobrino, J. “El Ellacuría olvidado. Lo que no se puede dilapidar”, en Revista Latinoamericana de Teología, Núm. (XX) págs.

- Sobrino, J. "El pueblo crucificado" y "la civilización de la pobreza", "El hacerse cargo de la realidad" de Ignacio Ellacuría. Revista Latinoamericana de Teología, Núm. XX (XXX) págs. 209-228.

- Tamayo, J.J. (2014) “Ellacuría vive”, El País, 15 de noviembre de 2014. 


\section{Notas}

1 Texto leído el 6 de noviembre de 2019 en la Universidad I beroamericana Puebla en el marco de la conmemoración del 30 aniversario del asesinato de Ignacio Ellacuría y sus compañeros mártires.

2 Es cierto que el acceso a la obra de Ellacuría ha sido posible por un meritorio esforzado empeño editorial UCA/Editores, la editorial de la Universidad Centroamericana "José Simeón Cañas" en San Salvador, El Salvador de la que Ellacuría fue rector los últimos diez años de su vida. Sin embargo, quizá aún le haga falta mayor difusión. En todo caso, lo cierto es que en los últimos treinta años se han ido acumulando de manera sostenida "estudios, monografías, tesis doctorales, congresos, conferencias, investigaciones, cursos monográficos, círculos de estudio, Cátedras universitarias con su nombre, que demuestran la autenticidad de su vida y la creatividad y vigencia de su pensamiento en los diferentes campos del saber y del quehacer humano: política, religión, derechos humanos, universidad, ciencias sociales, filosofía, teología, ética, etcétera" (Tamayo, 2014). No sale sobrando comentar que este evento precisamente forma parte de ese esfuerzo por mantener actual el aporte de este extraordinario personaje jesuita que hoy nos convoca. Sobre su producción editorial cabe mencionar: "En 1990 y 1991 aparecieron dos de sus libros mayores, Conceptos fundamentales de la teología de la liberación, de la que es editor junto con su compañero Jon Sobrino, entonces la mejor y más completa visión global de dicha corriente teológica latinoamericana y Filosofía de la realidad histórica, editada por su colaborar Antonio González cuyo hilo conductor es la filosofía de Zubiri, pero recreada y abierta a otras corrientes como Hegel y Marx, leidos críticamente. Es parte de un proyecto más ambicioso trabajado desde la década de los setenta del siglo pasado y que quedó truncado con el asesinato. Posteriormente la UCA publicó sus Escritos politicos, 3 vols., 1991; Escritos filosóficos, 3 vols., 1996, 1999, 2001; Escritos universitarios, 1999; Escritos teológicos, 4 vols., 2000-2004" (Tamayo, 2014).

3 Si el lector desea ampliar un poco más esta dimensión del Ellacuría público recomiendo dos textos: el de Víctor Flores García y el de Rubén Aguilar Valenzuela cuyas referencias están al final en la sección correspondiente de este trabajo.

4 "La teología de la liberación ha sido un intento muy serio y bien logrado de reconceptualizar la totalidad de la fe cristiana desde la perspectiva de las necesidades de liberación de los pobres y oprimidos. Eso que Puebla denominó como la "opción preferencial por los pobres" y que llevó a poner en primer plano de su discurso el problema de la injusticia social en el mundo. Desde este punto de partida se redefinen y llenan de nuevos contenidos los ejes temáticos de la teología tradicional...teodicea, eclesiología, cristología, espiritualidad, pecado, etcétera". (Sermeño, 2002-2003: 95).

5 Algo similar cabría decir de la cobertura que se da a los actos terroristas en los países ricos, centrales y hegemónicos y a los actos similares (aunque con muchas más bajas) que ocurren en los países pobres y periféricos. Ellacuría siempre denunció esta hipocresía que establecía niveles de reconocimiento a los seres humanos haciendo a unos más valiosos y defendibles que a otros. Es decir, los ciudadanos de los países ricos frente a los de los países pobres.

6 "Misión actual de la Compañia de Jesús" es el borrador de un documento redactado por Ellacuría que vio la luz póstumamente y que contiene lineamientos para orientar la conversión de la Compañía de Jesús al mundo de los pobres. Es pues un documento con algunas propuestas concretas de cambio. (Ellacuría, Escritos Teológicos IV, 2001: 235-250).

7 Ellacuría atestiguo su despliegue en los años ochenta pero ya no pudo ver la agudización que alcanzo a lo largo de los noventa y hasta la crisis de 2008. 
8 "Nunca los ricos han sido tan ricos: $82 \%$ de la riqueza generada en 2017 terminó en manos del $1 \%$ e la población del mundo". Informes de la ONG OXFAM a nivel mundial y para el caso mexicano (Gerardo Esquivel). (falta completar referencia). Existen datos similares para México: ... 